\title{
ARQUEOLOGIA PRÉ-HISTÓRICA DO URUGUAI: UMA REVISÃO
}

Klaus Hilbert

\section{RESUMO}

A proposta deste trabalho é oferecer uma visão de conjunto das tradições indígenas pré-históricas mais significativas do Uruguai, partindo das tradiçōes antigas do paleoíndio até chegar aos tempos da conquista.

Ainda que o material documentado apresente um volume certamente considerável, não pretendemos esgotá-lo, ao contrário, esperamos que esta exposição constitua um incentivo para discussões e futuras investigações.

As indústrias líticas no Uruguai podem ser divididas em duas tradições; uma chamada de caçadores superiores especializados (antigo e tardio) com pontas de projétil e a outra de caçadores-coletores primitivos sem pontas de projétil. Em geral, se considera esta última como a tradição mais antiga e se propõe uma datação que cronologicamente associa-se com o último glacial, enquanto a tradição com pontas de projétil é datada em aproximadamente 10.000 A.P. Mas, no Uruguai, não existem pontos de apoio, datações por $\mathrm{C}^{14}$ por exemplo, que permitam supor um datação antiga da tradição dos caçadores-coletores primitivos. Para o Catalanense 
e o Cuareimense, as indústrias mais importantes correspondentes a esta tradição, estima-se uma antigüidade entre 9.000 e 2.000 A.P. A maioria dos sítios destas duas indústrias localizam-se no norte do país, caracterizando-se o Catalanense por ser uma indústria bifacial com machados de mão toscos de grande tamanho, e o Cuareimense por choppers e chopping-tools, raspadores plano-convexos e, em geral, pelo trabalho unifacial de seus artefatos.

Pontas pedunculadas "rabo de peixe" são consideradas como os instrumentos típicos dos grupos de caçadores-coletores paleoindígenas e foram encontradas no Uruguai em sítios de superfície localizados no rio Negro médio e na costa Atlântica.

Associados à tradição antiga dos caçadores-coletores especializados, conhecemos no Uruguai somente dois sítios: Tigre e Calpica, os quais foram escavados durante as investigações realizadas pela "Missão de Resgate Arqueológico de Salto Grande", na zona do rio Uruguai médio, com datações por $\mathrm{C}^{14}$ de 10.400 A.P.

Sítios da tradição tardia dos caçadores superiores especializados encontram-se em grandes quantidades ao longo do rio Uruguai, o rio Negro e seus afluentes e na costa Atlântica. As datações variam entre 7.000 A.P. até 2.000 A.P.

Os portadores da cerâmica da cultura Entrerriana foram grupos caçadores-coletores e pescadores, que habitaram em pequenos cerritos em zonas de banhado ou ao longo dos rios. A cerâmica têm antiplástico de areia, compreende formas globulares, subglobulares e pratos com decoração incisa ponteada e linhas retas ou em zig-zag.

A cultura dos Ribeirenhos Plásticos se sobrepõe à cultura Entrerriana, desenvolvendo-se a partir desta e acrescentando a decoração plástica, o sulco rítmo e a pintura vermelha aplicada pós-cocção, geralmente em bandas.

As formas dos recipientes se mantém, somando-se os vasilhames tubulares e as campanas.

Os sítios correspondentes a estas culturas se distribuem ao longo do rio Uruguai, na desembocadura do rio Negro, descendo para o Uruguai até alcançar a altura da cidade de Montevidéu.

A tradição Tupiguarani instalou-se nesta região aproximadamente até 500 d.C. portando, uma cerâmica que, na decoração, se caracteriza por apresentar o corrugado, ungulado, escovado e por ser polícroma. Os 
achados desta tradição foram encontrados principalmente ao longo do rio Uruguai, rio Negro, rio Prata e na costa Atlântica. A tradição Tupiguarani e a cultura dos Ribeirenhos Plásticos coexistem nesta região até a chegada dos conquistadores. A cerâmica missioneira foi localizada na desembocadura do rio Negro, em Salto Grande e no alto rio Negro.

\section{TRADIÇÕES LÍTICAS NO URUGUAI}

Até o final do século passado, o paleontólogo argentino Florentino Ameghino (1959) sustentava que o Homo sapiens sapiens era oriundo do continente americano (Homunculus patagonicus), podendo-se retroceder em busca de suas origens até o Terciário. Ameghino adotou esta idéia devido, entre outros indícios, aos achados simultâneos de instrumentos líticos a partir de seixos pertencentes tipologicamente ao Paleolítico inferior (choppers e chopping-tools) e ossos da fauna fóssil correspondentes ao Eoceno (Formação Pampeana), desconsiderando outras particularidades destes achados, tais como deslocamento e processos de erosão do terreno. Este detalhe já foi notado por José Figueira (1892). Em sua obra sobre as culturas pré-colombianas do Uruguai, apresentada em comemoração ao $400^{\circ}$ aniversário do descobrimento da América, em Madri, Figueira menciona que os achados de Ameghino efetuados no Cerro de Montevidéo (neste caso lascas e restos fósseis) não podiam provir da mesma camada geológica. $\mathrm{O}$ material lítico pertencia à um sítio pré-colombiano localizado imediatamente sobre as encostas que haviam erodido pouco tempo antes. Os fósseis em geral, possuíam uma origem terciária. A teoria de Ameghino da grande antigüidade do Homem Americano, foi duramente criticada e descartada por outros cientistas contemporâneos, como, por exemplo, Alex Hradlicka (1912).

No seu intento de classificação das tradições líticas, Gordon Willey (1971, 1978) ordenou cronologicamente as tradições com instrumentos em lascas (flake tradition) como sendo mais antigas do que as tradições de choppers e bifaces (biface tradition), seguidas pelas tradiçōes tecnologicamente mais avançadas do paleoíndio, com pontas de projétil acanaladas e trabalhadas bifacialmente (fish-tail).

O que caracteriza a tradição de lascas é a falta de instrumentos trabalhados bifacialmente. Pertencem ao inventário desta tradição, as 
lascas simples retocadas, instrumentos denticulados, raspadores e picões.

Divergindo do modelo evolucionista proposto por Willey, a partir de uma série de desenvolvimentos nos aspectos tecnológicos, Alex Krieger (1964) ordenou as tradições sem pontas de projétil bifaciais como um "estágio de pré-pontas de projétil" (pre-projectil stage). Este estágio de pré-pontas de Krieger implica em certo condicionamento tecnológico, que não se encontra determinado temporalmente e pode chegar até tempos recentes.

De acordo com Menghin (1956, 1957), Bormida (1964), Taddei (1980, 1987), Hilbert (1991) e outros, as indústrias líticas no Uruguai podem ser divididas em duas tradições: uma chamada de caçadores superiores especializados com pontas de projétil e a outra de caçadorescoletores primitivos sem pontas de projétil. Não existem provas conclusivas que atestem a correspondência desta corrente com uma datação antiga, como coloca Willey, por exemplo. Ao contrário, no Uruguai, todas as datações antigas obtidas pelo método radiocarbônico estão associadas com as tradições de caçadores superiores especializados.

Nos inclinamos a crer na existência de um desenvolvimento paralelo destas duas tradições líticas, como sugere Krieger com seu modelo de estágios. No sul do Brasil, por exemplo, existem indícios que permitem supor que os caçadores superiores especializados (Umbú) elegeram a zona de campo ou pradaria para viver, enquanto que os caçadorescoletores primitivos (Humaita) habitaram, preferencialmente, zonas de matas (Schmitz, 1978, 1984; Ribeiro, 1979, 1990, 1991; Kern, 1981, 1983-84, 1991, Rodriguez, 1992).

\section{CAÇADORES-COLETORES PRIMITIVOS}

\section{Catalenense}

A indústria lítica do Catalanense foi descoberta por Antonio Taddei e apresentada no $33^{\circ}$ Congresso Internacional de Americanistas na Costa Rica. Logo seguiram outras publicações. Deve-se notar que não existe nenhuma outra indústria lítica da pré-história uruguaia sobre a qual se tenha publicado tanto e durante tanto tempo (Campá-Soler et alli, 1959, 1962; Chebataroff, 1961; Bormida, 1964; Taddei, 1987). 
Os sítios do Catalanense foram visitados repetidas vezes por delegações nacionais e estrangeiras, e foram os trabalhos de descrição e classificação de Taddei que permitiram uma ampla difusão e conhecimento desta indústria, inclusive a nível internacional.

Nas nascentes do arroio Catalan Chico (Depto. de Artigas), cobrindo uma área de aproximadamente $28 \mathrm{~km}^{2}$, foram localizados cerca de 20 sítios arqueológicos. Só a coleção de Taddei possui mais de 22.000 artefatos do Catalanense. Todos os sítios conhecidos do Catalanense são de superfície e contam com uma enorme quantidade de artefatos líticos.

Propõe-se para a indústria do Catalanense a divisão em duas fases distintas: uma mais antiga, que possui lascas grandes, e outra fase mais recente, com maior quantidade de objetos bifaciais. Este esquema é equivalente ao modelo proposto por Willey (1971), que postula a existência de uma tradição de lascas seguida por uma tradição de bifaces. O Catalanense antigo é datado por Bormida, através dos terraços pluviais e das oscilações eustáticas, em 9.000 A.P., datando-se a fase mais recente aproximadamente em 7.000 A.P.

A partir do exame de parte do material da coleção Taddei - Sítios Brunn, Cina-Cina, Falcon e Paso-Tala - , consideramos que o Catalanense pode ser caracterizado mais pelos elementos técnicos do lascamento, do que através das classificações detalhadas das formas das peças retocadas e de suas porcentagens. $\mathrm{O}$ elemento característico do Catalanenses é o lascamento bifacial. Lascas com plataforma facetada primária e secundariamente - e negativos de lascas que convergem em um ponto central são elementos típicos produzidos por lascamentos de núcleos discoidais, que possuem características de técnica de um proto Levallois.

Ainda de que se possa partir da inferência de que esta indústria de caçadores-coletores primitivos se manifesta sobretudo no norte e noroeste do país, onde há uma maior concentração de sítios do que em outros lugares, a surpreendente densidade de sítios localizados na zona de Catalan Chico é produto do desenvolvimento das investigações arqueológicas.

Indústrias bifaciais comparáveis com o Catalanense estão distribuídos por toda América do Sul. As variaçōes tipológicas dos bifaces inclui, desde exemplares toscos de forma oval ou triangular, semelhantes à machados de mão do Paleolítico médio, até objetos compridos e finos. 
Pertencem também ao inventário desta indústria, raspadores toscos e instrumentos denticulados. Com exceções, tratam-se de sítios de superfície, como no caso do Catalanense. Desta forma, o estabelecimento de uma cronologia para estas indústrias em geral e a elaboração de uma série cronológica, baseada nos distintos tipos de bifaces em particular são tarefas muito difíceis de serem executadas.

\section{Cuareimense}

O Cuareimense é uma indústria lítica sem pontas de projétil e pertence, como o Catalanense, à tradição dos caçadores-coletores primitivos. Geograficamente, se localiza no norte do país (Depto. Artigas) e todos os sítios se encontram sobre as margens do rio Quaraí. As barrancas deste rio, situados em frente a cidade de Quaraí, foram pela primeira vez estudadas intensamente por Jorge Chebataroff (1961) e, no ano de 1964, foi Bormida quem, junto com uma detalhada descrição morfológica destas mesmas barrancas, definiu a indústria lítica desta região.

No sítio de Puerto, localizado em frente a cidade de Quaraí, realizamos, no ano de 1979 , uma escavação, contando com o apoio da Prefeitura Municipal de Artigas (Hilbert, 1985a). No decorrer destas investigações, encontramos à $1 \mathrm{~m}$ de profundidade, uma camada de ocupação, que corresponde à camada II de Bormida. Este já a havia considerado como a camada arqueológica principal, devido a sua maior densidade de artefatos.

Encontramos dificuldades de classificação na indústria lítica do Cuareimense, principalmente na distinção entre núcleos e instrumentos, já que, neste contexto, a definição destes tipos de artefatos é, em princípio, flexível. Se reconhecermos como instrumentos aqueles núcleos que posteriormente receberam retoques, qualquer núcleo poderá ser considerado como instrumento.

Excluindo-se estes casos duvidosos, existem lascas com retoques claramente definidas como instrumentos. Os retoques não causam uma grande impressão: são grandes, distanciados uns dos outros e lascados por percussão direta; não se encontram retoques à pressão. Associam-se ao inventário Cuareimense, aqueles instrumentos nucleiformes, arredondados e ovalados, com finos retoques acompanhando a borda da peça. Por 
seus cuidadosos retoques, estes exemplares parecem obedecer a uma determinada forma. Outros instrumentos típicos são os lenticulados, elaborados a partir de seixos. Estes apresentam marcas de utilização, que os assinalam como percutores; também poderiam tratar-se de moedores. O trabalho bifacial dos artefatos, como é típico para a Catalanense, não existe nesta indústria. (Austral, 1982).

Pela análise do $\mathrm{C}^{14}$ de um carvão retirado de um dos fogões da escavação acima citada, obteve-se a datação de $1.560 \pm 50$ A.P. Esta data é compatível com a idéia de uma datação antiga para a tradição de lascas de Willey. Desta única prova não se pode derivar nenhuma datação aplicável para o Cuareimense em geral. Vários indícios sinalizam em favor de uma grande duração desta indústria.

No nível de ocupação encontrado durante a escavação em 1979, foram encontrados 2 núcleos do tipo Cuareimense bastante erodidos, um dos quais se apresentava reaproveitado, como indica uma série de negativos mais recentes. Outra amostra de $\mathrm{C}^{14}$ foi tomada na base de um paleocanal. Tratava-se de grandes fragmentos de carvão vegetal, que foram encontrados junto a um típico núcleo Cuareimense. Esta amostra de $\mathrm{C}^{14}$ data eventualmente o material Cuareimense, que foi redepositado neste paleocanal, junto ao carvão vegetal. A datação de $4.410 \pm 130$ A.P. reafirma a permanência desta indústria durante um grande período sem grandes mudanças tipológicas, fato já suspeitado por Bormida.

\section{TRADIÇĀO PALEOÍNDIO \\ (Pontas "rabo de peixe")}

Os primeiros indícios de que a América do Sul já estava povoada no começo do último glacial foram oferecidos nos anos 30 por Bird (1938, 1946). Nas grutas da Terra do Fogo, como Palli Aike e Fell's Cave, Bird encontrou, junto com restos de ossos humanos, ossos de Milodonte e cavalos extintos, pontas "rabo de peixe", raspadores e instrumentos em osso. A datação de $\mathrm{C}^{14}$ mais antiga para estes restos é de $11.000 \mathrm{AP}$ (Schobinger, 1969). Nos anos 50, José Emperaire, Annette LamingEmperaire e Henri Reichlen (1963) realizaram outras escavações em Fell's Cave, confirmando suas observaçōes com aqueles resultados obtidos por Bird. 
Pontas pedunculadas com "rabo de peixe" são consideradas instrumentos típicos dos grupos paleoíndios e foram encontradas no Uruguai em sítios de superfície situados no rio Negro médio e na costa atlântica (Bosch et alii, 1980).

\section{CAÇADORES-COLETORES ESPECIALIZADOS}

\section{Tradições antigas com pontas de projétil}

Existem alguns sítios que apresentam um inventário muito similar, do ponto de vista tecnológico, com aqueles que pertencem a tradição do paleoíndio. No entanto, embora possuindo datações de $\mathrm{C}^{14}$ comparáveis com as atribuídas ao paleoíndio, carecem de pontas pedunculadas "rabo de peixe".

Associados à tradição antiga dos caçadores-coletores especializados, conhecemos no Uruguai somente dois sítios: Tigre a Calpica, os quais foram escavados durante as investigações realizadas pela "Mission de Resgate Arqueológico de Salto Grande", na zona do rio Uruguai médio (Hilbert, 1985b, 1991). Por outro lado, são conhecidos mais de 20 sítios situados na região do alto Uruguai, no Rio Grande do Sul (Miller, 1967, 1976, 1987), cujo material corresponde à fase Uruguai e foi datado por $\mathrm{C}^{14}$ entre 10.400 e $9.600 \mathrm{AP}$. Nestes sítios foram encontradas pontas de projétil com aletas e pedúnculo reto. Também foram localizados outros tipos de pontas, juntamente com um grande número de raspadores, instrumentos trabalhados bifacialmente, ferramentas toscas nucleóides e, esporadicamente, alguns choppers.

\section{Tradição tardia com pontas de projétil}

O inventário dos sítios aqui arrolados exibe, geralmente, paralelismo com a tradição Umbu, no Rio Grande do Sul, e as pontas de projétil mostram grandes similitudes com as pontas patagônicas dos períodos Megallan III e IV (Bird, 1946; Miller, 1969). 
Região do rio uruguai e afluentes

Nas investigações da "Mission de Resgate Arqueológico de Salto Grande", escavamos o sítio K 86 . Este se encontra a $1 \mathrm{~km}$ rio acima do sítio do Tigre e localiza-se sobre um albardão do rio Uruguai. Ali foi encontrada uma camada de ocupação com pontas pedunculadas e pontas foliformes ovaladas, que tipologicamente se associam com as pontas do sítio Tigre. Igualmente o inventário restante, ainda que quantitativamente menor, não mostrou maior diferença com a fase Tigre. Para o último nível deste sítio temos uma datação $\mathrm{C}^{14} \mathrm{de} 6760 \pm 100 \mathrm{AP}$ (Hilbert, 1985b). Esta datação apóia nossa idéia de que ocorreu uma transição paulatina entre esta tradição antiga com pontas de projétil e aqueles sítios com elementos da tradição Umbu.

Ao longo de uma campanha de escavações de resgate no sítio Bañadero realizada pelo CEA (Centro de Estudios Arqueológicos) e o Museu de História Natural da Prefeitura Municipal de Salto, efetuaramse investigações na ilha de Arriba, na ilha do Médio e nas costas apostas.

Outros sítios, dos quais provém estes mesmos tipos de pontas, são os da ilha de Verdum, Boycoa, Espinillar e Herviero. O sítio Pedra Pelada, descoberto por Gregório Laforcada (1974), no ano de 1947, está localizado a $20 \mathrm{~km}$ das Termas do Arapey (Depto de Salto) sobre uma extensa placa de basálto. Ali foram encontradas cerca de 140 pontas pedunculadas. Durante os trabalhos da "Mission de Resgate Arqueológico de Salto Grande", foram efetuadas várias sondagens e cortes de até 2,5 m de profundidade. Nas diversas camadas de ocupação foram localizados alguns fogões e oficinas com pequenos agrupamentos de micro lascas, com data de $\mathrm{C}^{14}$, para o piso de ocupação, de $5.030 \pm 110$ AP. (Guidon, 1979).

Região do rio Negro e rio Tacuarembó

Ao longo do rio Negro foi encontrado um grande número de sítios arqueológicos, em sua maioria de superfície, localizados entre dunas. Esta região apresenta arqueologiamente um aspecto homogêneo. Já desde o ano de 1945, Taddei interessou-se por esta zona, percorrendo e examinando muitos sítios. Entre estes destacam-se Palmar de Mujica, Navarro, Paso del Puerto, Enramada, Aguila Chica, Ramirez, Paso Porrua, Quinteros, Sauce, Rincon de Cabrera, Isla Rospide, San Gregorio 
(Polanco) e Paso Ramirez. No total são aproximadamente 40 sítios que se distribuem ao longo do curso do rio Negro médio (Taddei, 1969, 1977; G.A.L.Y., 1982).

Instrumentos característicos destas zonas são as pontas pedunculadas, sendo a forma dominante similar a de Megallan IV (Bird, 1946). O inventário restante dos instrumentos lascados se completa com raspadores plano-convexos, perfuradores, lascas com finos retoques laterais e bifaces toscos incompletos. $\mathrm{O}$ material chama a atenção por ser freqüentemente denticulado; os entalhes e as pontas correspondentes assinalam a presença de marcas de utilização. Os artefatos são em geral pequenos, especialmente os raspadores plano-convexos, este fator está ligado às proporçōes da matéria-prima disponível. Outro grande grupo de instrumentos está constituído por moedores, polidores e percutores. Estes instrumentos são característicos dos caçadores superiores especializados da região do rio Uruguai médio, rio Negro, rio Taquarembó e a costa Atlântica. Enquanto que nas pontas de projétil, em geral, existem diferentes tipologias: entre as zonas do noroeste (rio Negro e Uruguai) e a costa Atlântica estes instrumentos de moer se encontram determinados por um elemento funcional e técnico (Baeza et alli, 1974).

\section{Região da costa Atlântica}

A história das investigações arqueológicas no Uruguai está intimamente relacionada com o descobrimento e reconhecimento dos "paraderos" da costa atlântica. Sítios como La Coronilla, Cabo Polônio, Valizas, Punta del Este, etc. encontram-se citados pela primeira vez por Figueira (1982), que realizou uma avaliação sistemática e científica dos mesmos.

Ainda que seja imensa a quantidade de material encontrado entre a zona do Chuí e Montevidéu, são escassas as descriçōes da localização exata dos artefatos. Encontramo-nos, então, com grandes listas de material numerado, onde se menciona, por exemplo: "entre Valizas e a Caronilla", tratando-se, neste caso, de uma distância de mais de 140 km entre um ponto e outro.

Nesta faixa costeira foram encontrados objetos cujas estimativas cronológicas cobrem um período de cerca de 12.000 anos: desde as peças pertencentes ao período paleoindígena (pontas "rabo de peixe"), achados 
correspondentes à tradição bifacial, pontas de projétil similares ao complexo Megallan IV e V, passando pelas primeiras tradiçōes cerâmicas datadas ao redor do ano 2.000 A.P., até chegar àqueles fragmentos cerâmicos característicos da tradição Tupiguarani e aos vestígios que marcam os primeiros contatos com a cultura européia.

Um grande empecilho para concluir um trabalho de análise e classificação está no fato de que estes sítios de superfície da costa Atlântica têm sido, desde há mais de 100 anos, objetos de sucessivas coletas, e o material se encontra disperso em distintas coleções privadas, mesclando-se em parte, com o material de outros sítios, e tendo inclusive algumas peças extraviadas. Além disso, em muitas das coleçōes a que tivemos acesso, constatamos que não continham a totalidade do material, mas que ocorreu uma seleção do mesmo no momento da coleta, ou seja, que não nos encontramos frente ao inventário real do sítio. Foram coletados principalmente as peças que consideradas mais bonitas e interessantes, como, por exemplo, pontas de projétil, morteros, bolas de boleadeira, etc. e, muitas vezes, hoje estas se encontram agrupadas tipologicamente e sem nenhuma referência à sua localização. Assim temos caixas e mais caixas cheias nos depósitos dos museus.

Considerando as razões expostas anteriormente, as afirmações que podemos efetuar sobre estes achados serão muito sumárias.

Partimos da idéia de que a presença de pontas de projétil no inventário é um indício que nos permite considerá-lo como pertencente a tradição dos caçadores superiores especializados.

Podem-se distinguir duas formas principais de pontas de projétil ainda que estes tipos não sejam rígidos e as transições sejam possíveis.

Se as comparamos com as pontas da zona do rio Uruguai e do rio Negro, o que chama a atenção nestas pontas em geral é que os retoques foram toscamente efetuados, apresentando um fio muito irregular, dando a impressão de um trabalho descuidado.

As culturas dos grupos de caçadores e coletores, assim como também as posteriores culturas ceramistas, têm em comum aqueles instrumentos de moer, mós e mãos-de-pilão, quebra-coquinhos, etc.

Para a maioria destes instrumentos, a forma final foi determinada pelo uso. Nestes instrumentos podemos verificar a presença de dois tipos de marcas de utilização. Por um lado, depressōes que foram produzidas mediante golpes ou picoteado e, por outro, marcas originadas por friç̧ão 
ou alisamento. No primeiro caso a superfície do artefato se apresenta com cicatrizes e pequenas fraturas, enquanto que, no último a superfície está polida e alisada (Mapa: 1).

\section{TRADIÇÕES CERAMISTAS NO URUGUAI}

No final dos anos 40, Gordon Willey afirmava que as primeiras tradições cerâmicas da região Pampa-Paraná podiam ser datadas ao redor de 1550 A.P. (Howard \& Willey, 1948).

Eduardo Cigliano (1966) encontrou um sítio em Palo Branco na costa norte da província de Buenos Aires. Este concheiro, redepositado junto com fragmentos de cerâmica simples e erodida, está localizado sobre uma antiga linha costeira. Os moluscos da camada inferior foram datados em 4.760 A.P. \pm 120. José Brochado (1984) propõe que a dispersão desde Palo Branco subira pela costa em direção norte, considerando a tradição Vieira como a continuação desta tradição.

Segundo nossas informações, os fragmentos cerâmicos mais antigos do Uruguai, datados por $C^{14}$ provém dos Sítios da região de Salto Grande: ilha de Arriba $2.350 \pm 80$ A.P. (Baeza, et alli, 1977; Guidon, 1979) e a fase Tigre $1810 \pm 45$ A.P. (Hilbert, 1985, 1990). Trata-se de uma cerâmica com antiplástico de areia, irregularmente queimada, mal alisada, decorada com incisões (Salto Grande inciso), ponteada e escovada (Diaz et alli, 1975, 1977).

\section{A tradição Vieira}

Os poucos achados cerâmicos dos "paraderos" da costa Atlântica vinculam-se estreitamente com a tradição Vieira, recebendo o nome nesta região de fase Ceibo (Prieto et alli 1970). Estes fragmentos procedem, como em geral tơda a cerâmica da tradição Vieira, dos cerritos (Cabrera et alli, 1984). As vasilhas da fase Ceibo contém como antiplástico areia de quartzo, e os escassos fragmentos decorados exibem na sua maioria motivos simples ponteados e incisões. As formas dominantes dos recipientes são as globulares e subglobulares, aparecendo alguns pratos.

A tradição Vieira estende-se sobre a região das grandes lagunas e os banhados no Rio Grande do Sul, incluindo o noroeste Uruguaio, ou seja, a área de dispersão dos cerritos (Schmitz \& Baeza, 1982; Cabrera \& 
Femenias, 1991). Dentro da tradição propriamente dita distinguem-se 3 fases, cujas datas de $\mathrm{C}^{14}$ são: para a fase Vieira I, 1.350 A.P., para a fase II, 950 A.P., e para a fase III, 250 A.P. mesclada com cerâmica da tradição Tupiguarani - subtradição corrugada - e vestígios modernos de superfície (Naue, 1973; Branco, 1990; Schmitz, et alli, 1991). Na região do Rio Grande do Sul, no extremo sul da Lagoa dos Patos, temos investigações detalhadas sobre os restos alimentícios e ósseos localizados nos cerritos. Nas escavações realizadas foram encontrados ossos de pescado e restos de crustáceos de água doce, sendo freqüente a presença de ossos de pássaros e mamíferos. (Schmitz, 1976; Jacobus, 1991).

\section{A cultura Entrerriana}

As primeiras tentativas de sistematização das tradições cerâmicas correspondentes à região do Rio da Prata e do delta do Paraná foram realizadas por Luis Maria Torres (1911), que distinguiu 3 níveis cerâmicos: a cerâmica mais simples é supostamente a mais antiga, o segundo nível cerâmico é o que apresenta decoraçōes plásticas de influência Arawak e o mais recente é o da tradição Tupiguarani.

Para Samuel Lothrop (1932) não existe uma diferença cultural entre os dois primeiros grupos cerâmicos que justifiquem uma separação, mas assim a cerâmica primitiva e com representações gráficas pertence a uma mesma unidade cultural. Antonio Serrano, ao longo de diversas publicações $(1932,1933,1972)$ desenvolve um sistema com 3 níveis: a cultura Entrerriana ou básica da costa, cultura dos Ribeirenhos Plásticos que, desenvolvendo-se a partir da anterior, apresenta os típicos elementos decorativos plásticos, fazem do amplo uso do sulco rítmico (drang and jab) e pintura bícroma, e, por último, a tradição Tupiguarani.

Segundo Serrano, os portadores da cultura Entrerriana foram grupos de pescadores e coletores, que habitaram os.cerritos localizados ao longo dos rios ou banhados. A cerâmica da cultura Entrerriana apresenta geralmente antiplástico de areia, empregando como técnica decorativa o penteado e incisões, sendo os motivos mais freqüentes em zig-zag, gregas, ponteado em zonas, etc. $\mathrm{O}$ início desta cultura pode ser datado ao redor de 2.450 A.P., continuando em alguns sítios inclusive até os tempos históricos. 
No transcurso do tempo, a cultura Enterriana assimilou alguns elementos próprios da tradição dos Ribeirenhos Plásticos (sulco rítmico, vasilhas tubulares, etc.), permanecendo, não obstante, como unidade cultural paralela a esta tradição e a tradição Tupiguarani. As fases principais da cultura Entrerriana são a de Arroyo Sarandi, Ibicuí, Salto Grande e Colônia Concórdia.

\section{A fase Salto Grande}

Os sítios da região de Salto Grande foram mencionados pela primeira vez por Serrano (1932). Sobre a margem argentina, Serrano realizou uma série de investigaçōes, encontrando alguns artefatos líticos toscamente elaborados e fragmentos simples de cerâmica, na sua maioria sem decoração. Os poucos fragmentos decorados apresentavam motivos incisos em zig-zag e ponteados: Salto Grande inciso (Serrano, 1954; Rodríguez \& Rodríguez 1985).

Também foram encontrados ossos de mamíferos e um grande número de bivalves. Outras investigações foram realizadas por Cigliano, Schmitz e Caggiano (1971). Estes percorreram áreas em território argentino, assim como, também, as ilhas de Arriba, do Meio e das Flores. Nos sítios de El Dorado, Cerro Chico I e II, os Sauces e arroio Yarara foram encontrados, além da cerâmica típica Salto Grande Inciso, cerâmica com decorações plásticas e cerâmica da tradição Tupiguarani. Analisando os moluscos encontrados nestes sítios, foi possível extrair 2 datações de $\mathrm{C}^{14}$ : em Cerro Chico I, 1.055 A.P 35 e em Cerro Chico II, 1.180 A.P. \pm 70 ; datações estas, que marcam o final da tradição Salto Grande inciso ou o início da tradição dos Ribeirenhos Plásticos.

Para a fase Salto Grande obtiveram-se as seguintes dataçoes de $\mathrm{C}^{14}$ : Ilha de Arriba 2.370 A.P. \pm 80 e Ilha do Meio, 1.350 A.P \pm 80 . Para o nível cerâmico da fase do Tigre a datação foi de $\mathrm{C}^{14}$ de 1.810 A.P. \pm 45 (Austral, 1977; Baeza et alii, 1977; Guidon, 1979; Hilbert, 1985, 1990).

\section{A fase Ibicuí}

Os sítios conhecidos dos portadores da cerâmica correspondente à fase Ibicuí são: Paraná Pavon, Paraná Guazu, Brazo Largo, e aqueles na costa da província de Buenos Aires e ao longo da costa do rio Uruguai e do rio da Prata. 
A pasta da cerâmica da fase Ibicuí tem antiplástico de areia, de cor castanha, que internamente é mais escura. Dominam os recipientes de formas globulares, subglobulares e os pratos. A decoração da cerâmica da fase Ibicuí apresenta ponteados em zonas, formando motivos de xadrez retos ou em zig-zag, incisões com linhas irregulares em zig-zag, paralelas ou onduladas. Às vezes apresenta pintura vermelha após a cocção, aplicada em faixas paralelas à borda.

A cerâmica da fase Ibicuí foi encontrada no Uruguai nos seguintes sítios: barranca de São Gregório, Boca del rio Negro, Colonia San Javier, ilha Infante, ilha Vizcaino, Bocas del Moguer, Nueva Palmira (Depto. de Rio Negro), Rincón del Rey e Arroyo del Sauce (Depto. de Colonia), Paradero de las Tunas e Arazati (Depto. de San José), Rincón de la Teja (Depto. de Montevideo) e Laguna Blanca (Depto de Canelones). Todos estes sítios são a céu aberto.

Do sítio Paradero de las Tunas (Penino \& Sollazo, 1927), localizado sobre a margem direita do rio Santa Lucia (Depto. de San José), provém a maioria das informações publicadas sobre a fase Ibicuí. Os autores informam sobre restos de esqueletos desenterrados das dunas, junto com material lítico lascado (pontas de projétil) e polido (artefatos típicos da costa: percutores, bolas, mós, etc.) e ainda que, a maior parte dos achados, era composta por fragmentos cerâmicos.

\section{A fase Colônia Concórdia}

Incluímos a fase Colônia Concórdia como formando parte da cultura Entrerriana, já que representa estilisticamente a transição entre esta cultura e a dos Ribeirenhos Plásticos. A técnica de decoração do estampado (impressão de um instrumento com ponta quadrangular) nos lembra, em seus motivos o Ribeirenho Plástico ponteado, ainda que as aplicações realizadas não se possam comparar aos desta tradição, já que se limitam a bandas de apliques arredondados formando ondas ou círculos.

Os cerritos de Colônia Concórdia se encontram sobre a margem esquerda do rio Uruguai no Departamento de Soriano.

Desde o final da década dos anos 40, os cerritos de Colônia Concórdia exerceram uma grande atração sobre os estudiosos da Arqueologia. Uma publicação mais extensa foi efetuada por Rodolfo 
Maruca Sosa (1957), na qual expōe principalmente sua própria coleção e partes da coleção Taddei. Um amplo informe, que se refere principalmente à cerâmica da dita coleção, foi publicado por membros do CEA (Diaz et alli, 1974).

A cerâmica é um fator muito importante na determinação do acervo cultural e cronológico deste sítio. O inventário lítico está composto, como em outros sítios cerâmicos, por exemplo, os cerritos da costa Atlântica -, pelos já conhecidos instrumentos polidos (bolas de boleadeiras, mós, etc.). Também aqui os artefatos líticos lascados são relativamente escassos e elaborados em sua maioria a partir de sílex, a matéria-prima mais abundante da zona.

Durante as campanhas de escavação foram recolhidos também ossos de restos alimentares, que até o momento não foram objeto de uma análise sistemática.

Maruca Sosa tratou de minorar esta carência e ilustrou, em uma lâmina bastante simplificada, o material lítico e cerâmico, junto aos distintos animais achados no cerrito de Colônia Concórdia (Sosa, 1957:181).

No total foram encontrados 50 esqueletos provenientes de enterramentos primários, dos quais foram analisados alguns exemplares pelo antropólogo Juan Muñoa e membros do CEA.

A cerâmica de Colônia Concórdia apresenta em geral antiplástico de areia, ainda que também contenha hematita triturada, restos vegetais carbonizados e espículas de esponjas de água doce (Uruguaya corallioides). Os fragmentos foram relativamente bem alisados, ainda que às vezes apresentem irregularidades no modelado das bordas e na espessura das paredes. A cocção foi irregular e a cor resultante é um castanho escuro com manchas claras, tendo o centro cinza escuro.

As técnicas básicas empregadas na decoração foram incisōes, aplicações, pintura, escovado e impressões. A decoração com sulco rítmico aparece muito esporadicamente e não constitui elemento característico da fase Colônia Concórdia, mas corresponde à cultura dos Ribeirenhos Plásticos.

As pontas ósseas constituem o grupo mais abundante dos artefatos de ossos trabalhados pertencentes a esta fase. A elaboração destes instrumentos foi relativamente simples, podendo-se reconstruir este processo através das marcas deixadas por sua produção. Utilizaram-se 
ossos longos de cervos, partidos longitudinalmente, e com a ponta polida. Pode-se reconhecer os distintos traços em bandas originadas por esta ação.

Os instrumentos para moer da fase Colônia Concórdia não se diferenciam daqueles encontrados na zona costeira do Atlântico ou na região do rio Negro. O inventário apresenta morteros, peças com depressão, mãos-de-pilão, bolas de boleadeiras e polidores (pedras com canaletas). A forma dos morteiros, característica daquela fase cerâmica, é subglobular e foi obtida mediante picoteado, sendo a superfície de trabalho circular. As mãos-de-pilão são de forma lenticular ou elipsóides e curtas. Como matéria-prima para a elaboração dos instrumentos líticos lascados foi empregado unicamente o sílex. O material lítico lascado é pouco abundante; os instrumentos retocados e com marcas de utilização se reduzem a uns poucos exemplares (Hilbert, 1991).

\section{Cultura dos Ribeirenhos Plásticos}

\section{Região da desembocadura do Rio Negro}

Junto as investigações realizadas na costa Atlântica, a região da desembocadura do Rio Negro, desenvolveu-se, sobre a influência de Figueira, como importante área de pesquisas arqueológicas. Em uma das freqüentes expedições realizadas, com participação de cientistas uruguaios e argentinos, o ano de 1892, foi descoberto e parcialmente escavado o cerrito da ilha Vizcaino (Figueira, 1892; Freitas, 1953). Em uma destas expedições foram encontradas duas urnas da tradição Tupiguarani e um esqueleto masculino com um colar de pérolas venezianas com faixas azuis e três discos de cobre (Hilbert, 1986).

Quase ao mesmo tempo foi descoberto o cerrito de La Blanqueada, sobre a margem esquerda do Rio Negro. A estes sítios mais importantes juntou-se, no ano de 1925, o cerrito da ilha Naranjo (Arredondo, 1927), seguido por toda uma série de sítios da ilha do Infante, Campo Galarza, La Blanqueada e Campo Morgan. A partir do ano de 1934 até a década de 60 , foi Maeso Tognochi quem se dedicou a percorrer intensivamente esta zona, coletando o material arqueológico. Suas escavações, sobretudo no sítio La Blanqueada, estavam orientadas principalmente para a obtenção de peças para completar sua coleção. Infelizmente os dados 
sobre o contexto dos achados e a localização geográfica dos mesmos são pouco confiáveis e inexatos, podendo-se somente utilizar esta coleção, que é uma das mais significativas do país, como apoio para corroborar outros sítios com informações mais seguras (Maeso, 1977; Tuya de Maeso, 1980).

O trabalho de Carlos A. Freitas sobre o material encontrado em La Blanqueada constitui um dos aportes mais valiosos para esta região. Apesar da pouca importância que outorga às diversas circunstâncias dos achados (posição estratigráfica, associações com outros artefatos, etc.), graças à sua análise detalhada e suas sistemáticas investigações sobre o material cerâmico, resulta de grande ajuda para a elaboração de uma classificação dos restos arqueológicos (Freitas, 1953).

A maioria dos sítios localizados ao longo do rio Negro e nas ilhas, quase 100 anos depois de seu descobrimento, encontra-se totalmente devastada, devido às escavações pouco sistemáticas, a ação dos diversos agentes erosivos, inundações, pisoteamento do gado, etc.

No intuito de ordenar tipologicamente e descrever a cerâmica da região da desembocadura no Rio Negro e da parte baixa do Uruguai, membros do CEA junto com arqueólogos brasileiros propõem a presença de tradições nesta zona: a tradição Yeguada, com cerâmica correspondente a tradição Tupiguarani, e a tradição Vizcaino associada às culturas dos Ribeirenhos Plásticos e elementos da cultura Entrerriana (Boretto Ovalle et alli., 1973).

Como mencionamos anteriormente, a cultura dos Ribeirenhos Plásticos desenvolve-se a partir da cultura Entrerriana, enriquecendo-a e modificando-a com a adição de novos elementos. Nos referimos especialmente às decorações plásticas zoomorfas e antropomorfas, a presença de vasilhames tubulares, o amplo uso do sulco rítmico nos motivos decorados, o freqüente emprego da pintura, que acrescenta cor branca ao tom vermelho já conhecido. A pasta e a forma dos recipientes se mantém igual a da cultura Entrerriana. O material ósseo está melhor elaborado e se encontram algumas peças que indicam a existência de contatos com as regiões sub-andinas.

Quanto às formas da cerâmica sem decoração dominam aqui, como também na cultura Entrerriana, as panelas globulares, subglobulares e os pratos, onde alguns exemplares apresentam o lábio para fora. 
Das diversas escavações realizadas nos cerritos de Campo Margon, La Blanqueada, ilha Infante e arroio Caracoles provém um grande número de instrumentos ósseos, em sua maioria pontas. Juntos às já conhecidas punções da fase Colônia, encontram-se diversas pontas ósseas de projétil, elaboradas a partir de fragmentos dos ossos longos com uma ranhura circunvalente para facilitar o encabamento. Outras pontas foram elaboradas com ossos completos e decoradas com motivos incisos cruzados em zig-zag.

Além dos portadores da cultura dos Ribeirenhos Plásticos, estes sítios na desembocadura do rio Negro, foram ocupados pelos representantes da tradição Tupiguarani, encontrando-se cerâmica corrugada e urnas polícromas. Ambas as tradições tiveram contato com a cultura européia, o que está demonstrado por vários achados e relatos históricos. Excluindo-se as já mencionadas pérolas venezianas e fragmentos de vidro, foram encontradas algumas peças de ferro (cravos e uma ponta de lança).

\section{Região de Salto Grande}

Foi durante as escavações realizadas por membros do Museu Municipal de História Natural de Salto Grande, principalmente nas ilhas de Arriba e do Meio, que os investigadores encontraram no Sítio Aruera (ilha de Arriba), a uns poucos centímetros abaixo da superfície, achados típicos correspondente à cultura dos Ribeirenhos Plásticos.

Uma datação radiocarbônica proveniente do corte 9 , entre 30 e 40 $\mathrm{cm}$ de profundidade, datou o material em 1.140 A.P. \pm 100 (Diaz et alli, 1977; Guidon, 1979). Junto às decorações da cerâmica com sulco rítmico, foram encontradas também alguns apliques zoomorfos. Destaca-se a localização de 3 vasilhames idênticos, quanto a forma e decoração, chamadas campanas ornitomorfas.

Além dos sítios correspondentes aos portadores da cerâmica dos Ribeirenhos Plásticos já apresentados - de Salto Grande e da região da desembocadura do Rio Negro -, os sítios mais importantes localizam-se sobre as costas do baixo rio Uruguai e rio da Prata. Alguns deles são: Colônia Agraciada, Villa Arena, Boca del Rosario, Juan Lacaze, Arroio del Sauce, Las Tunas, Arazati, etc. (Mapa: 2) 
MAPA 1 - Tradiçōes líticas do Uruguai

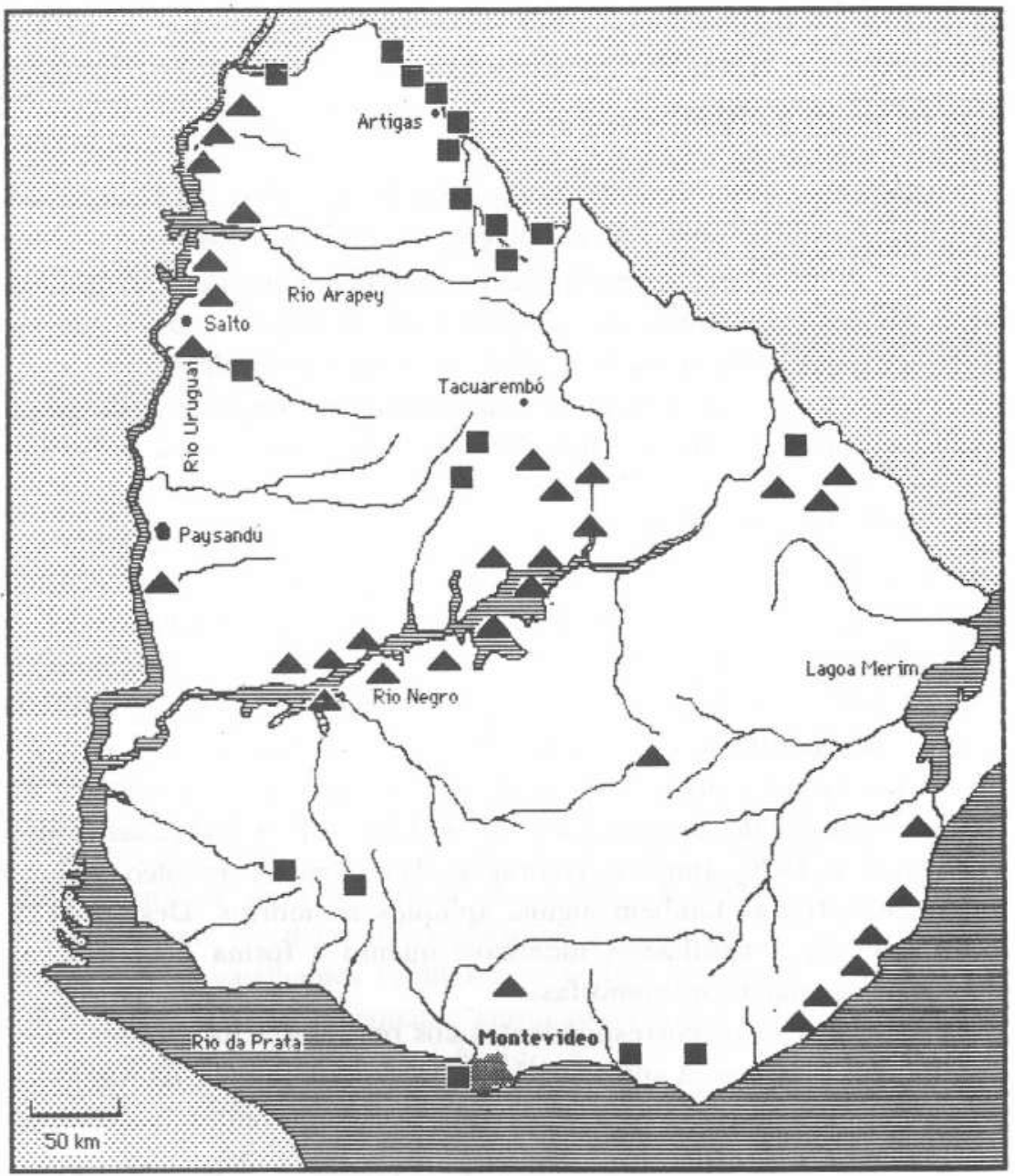

Sítios de Caçadores-coletores primitivos

Sítios de Caçadores-coletores superiores especializados 


\section{MAPA 2 - Tradições cerâmicas}

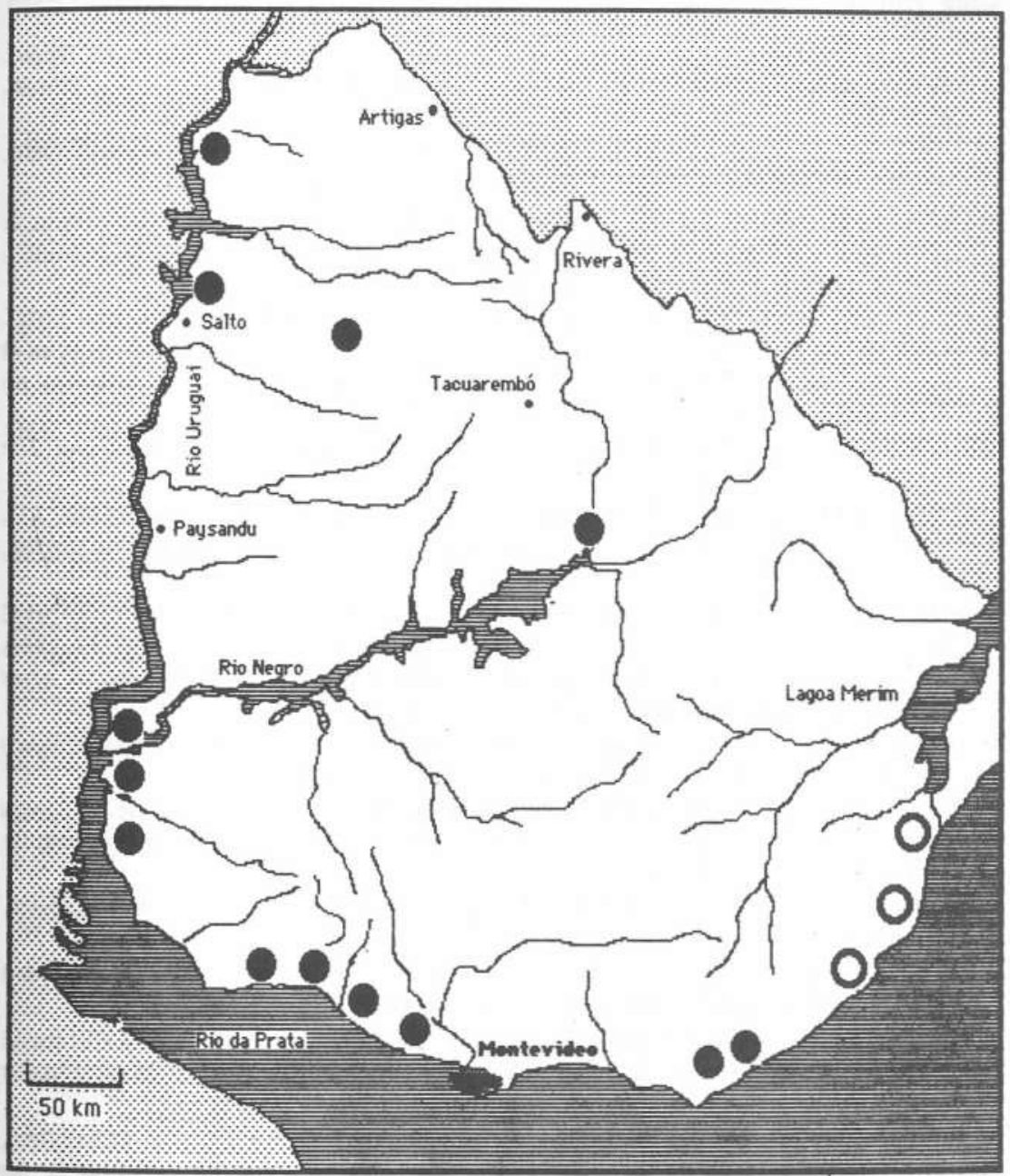

Sítios de Cultura Entrerriana e Riberenhos Plásticos

Sítios da Tradição Vieira 


\section{BIBLIOGRAFIA}

AMEGHINO, Florentino. 1959. La antigüedad del hombre en el Plata. Buenos Aires.

ARREDONDO, Horacio. 1927. Informe preliminar sobre la arqueología de la boca del Río Negro. Revista de la Sociedad "Amigos de la Arqueologia", v. 1, p. 6-45.

AUSTRAL, Antonio. 1977. Arqueología de urgencia en el yacimiento de Bañadero, Depto. de Salto, Uruguay. Actas do $5^{\circ}$ Encuentro de Arqueología de Litoral - Fray Bentos. p. 11-22.

. 1982. Informe sobre la segunda campaña arqueológica al Río Cuareim (Paypaso 1980). Actas do $7^{\circ}$ Congreso Nacional de Arqueología - Montevideo. p. 3-7.

BAEZA, Jorge; MOREMO DE BOSCH, Mobel; BOSCH, Ademar; PINTO, Milton \& FEMENIAS, Jorge. 1974. Informe sobre la zona costera atlántica de Cabo Polonio y Balizas. Actas do $4^{\circ}$ Encuentro de Arqueología del Litoral - Montevideo.

BAEZA, Jorge; TADDEI, Antonio; FEMENIAS, Jorge; RODRIGUEZ, Osvaldo; MELGAR, W.; DIAZ, Antonio \& FORNARO, M. 1977. Investigaciones arqueológicas en el áreas de Salto Grande. Tres primeros radiocarconos. Actas do 5 o Encuentro de Arqueología del Litoral - Fray Bentos. p. 69-88.

BIRD, Junius B. 1938. Antiquity and migrations of the early inhabitants of Patagonia. The Geological Review, v. 28, n. 2, p. 250-275.

. 1946. The archeology of Patagonians. In: Handbook of Southamerican Indians. J.H. Steward, ed. Bureau of American Ethnology, Smithsonian Institution, Bull., Washington, n. 143 , p. $17-24$.

BORETTO OVALLE, Rene; BERNAL, Romero; SCHMITZ, Pedro I. \& BASILE BECKER, Itala I. 1973. Arqueología del Depto. de Río Negro (R.O. Uruguay). Esquema tentativo de una secuencia cronológica para os sitios del Río Uruguay y Río Negro.Actas do $1^{\circ}$ Congreso Nacional de Arqueología - Fray Bentos.

BORMIDA, Marcelo. 1964. Las industrias líticas precerámicas del Arroyo Catalán Chico y del Río Cuareim. Revista di Scienze Preistoriche, Firenze, n. 19, p. 195-232.

BOSCH, Ademar; OLIVEIRA, Abel \& FEMENIAS, Jorge. 1980. Dispersíon de las puntas de proyectil líticas "psiciformes" en el Uruguay. Actas do $3^{2}$ Encuentro Nacional de Arqueología - Montevideo.

BRACCO, Roberto B. 1990. Dataciones $14 \mathrm{C}$ en sitios en elevación. Revista Antropológica, v. 1, n. 1, p. 11-7.

BROCHADO, José J. J. Proenza. 1964. An ecological model of the spread of pottery and agriculture in to eastern South America. (Tese de Doutorado) Illinois.

CABRERA PEREZ, \& FEMENIAS, Jorge 1991. Etnohistória y arqueologia en la Cuenca de la Laguna Merin: hacia la revisión de los modelos generales de área. Estudos Ibero-Americanos, v. 17, n. 1, p. 61-8.

CABRERA PEREZ, Leonel; BRACCO, Roberto B.; CURBELO, Carmen; FEMINIAS, Jorge; LOPEZ, José M. \& MARTINEZ, Eliane. 1964. Primeros resultados de las investigaciónes arqueológicas del norte de Depto. de Rocha, R. O. Uruguay. Montevideo.

CAMPA-SOLER, Raúl; TADDEI, Antonio \& CHEBATAROFF, Joerge 1959. Horizontes precerámicos en el Uruguay. Informe preliminar sobre una Cultura Precerámica en el Catalán Chico. Actas do $33^{\circ}$ Congresso Internacional de Americanistas - San José de Costa Rica. n. 2, p. 378-81. 
CAMPA-SOLER, Raúl \& VIDART, Daniel. 1962. El catalenense. Una industria de morfología protolítica en el Uruguay. Amerindia, Montevideo, n. 1, p. 2-28.

CHEBATAROFF, Jorge. 1961. El yamicimento lítico prehistórico del arroyo Catalán Chico. Revista Nacional, Montevideo, v. 6, n. 210, p. 78-92.

CIGliANO, Eduardo M. \& SCHMITZ, Pedro I. \& CAGgiANO, Maria A. 1971. Sitios cerámicos prehistóricos en la costaseptentrional de la Prov. de Buenos Aires y de Salto Grande y Entre Ríos. Anales de la Sociedad Científica Argentina, Buenos Aires, v. 129, p. 129-91.

CIGLIANO, Eduardo M.1966. La cerámica temprana en América del Sur. El yacimiento de "Palo Blanco" (Partido de Berisco, Prov. de Buenos Aires, Argentina). Ampurias v. 28, p. $163-70$.

DIAZ, Antonio; ROUCO, Cristina \& CAMPORA, Roberto. 1975. La cerámica de "Salto Grande", Uruguay. Actas do $2^{\circ}$ Congreso Nacional de Arqueología - Fray Bentos. p. 253-78.

DIAZ, Antonio \& BOSCH, Ademar \& MORENO de BOSCH, Mabel \& FEMENIAS, Jorge \& BECERRA, Oscar 1974. Los materiales arqueológicos del sitio Colonia Concordia. Actas do $3^{\circ}$ Congresso Nacional de Arqueología - Montevideo.

DIAZ, Antonio. 1977. Arqueología de Salto Grande: Secuencia cultural resultante de las investigaciones realizadas en Isla de Arriba e del Medio (Uruguay) Actas do $5^{\circ}$ Encuentro de Arqueología del Litoral - Fray Bentos. p. 155-64.

EMPERAIRE, José; LAMING, Annette \& REICHLEN, Henri. 1963. La Grotte Fell et autres sites de la région volcanoque de la Pataginie chilienne. Joumal de la Societé des Américanistes, n. 52, p. 167-255

FIGUEIRA, José H. 1892. Los primitivos habitantes del Uruguay en la Exposición Histórico-Americana de Madrid. Montevideo.

FREITAS, Carlos A. de. 1953. Algunos aspectos de la Arqueología de Uruguay. Revista de la Sociedad "Amigos de la Arqueologia", v. 12, p. 147-83.

G.A.L.Y. 1982. Informe preliminar del área del futuro lago de Palmar. Zona entre los arroyos la Violina y la Enramada. Actas do $7^{\circ}$ Congreso Nacional de Arqueología - Montevideo. p. 50-70.

GUIDON, Niéde, 1979. La sauvage archéologique de "Salto Grande". La Racherche, v. 10, n. 99 , p. $41-402$.

HILBERT, Klaus. 1985a. Das Cuareimense, eine Industrie ohne lithische Projektilspitzen aus Uruguay. Belträge zur Allgemeinen and Vergleichenden Archäologie, v. 7, p. 423-45.

. 1985b. Archäologische Fundplätze des Rio Uruguay, Tigre und des Mendigú, Republik Uruguay. Beiträge zur Allgemeinen und Vergleichenden Archäologie, v. 7, p. 447-561.

1986. Kupferschmuck vom Rio de la Planta. Marburger Studien zur Vor-und Frühgeschichte, v. 7, p. 81-90.

1990. Die Karamik der Fundplätze am Tigre, Rio Uruguay, Rep. Uruguay. Beiträge zur Allgemeinen und Vergleichenden Archaologie, n. 9-10, p. 381-91.

- 1991. Aspectos de la Arqueología en el Uruguay. Allgemeine und Vergleichende Archäologia-Materialien, 44.

HOWARD, Georg \& WILLEY, Gordon. 1946. Lowland Argentine Archaeology. Yale University Publications in Anthropology, n. 36, p. 5-60.

HRADLICKA, Ales. 1912. Early Man in South America. Smithsonian Institution, Bureau of American Ethnology. Bull. Washington, n. 52. 
JACOBUS, André L. 1991. Alimentos utilizados pelo homem na pré-história. Pesquisas (São Leopoldo) Antropologia, v. 6, p. 161-78.

KERN, Arno A. 1981. Le pré-céramique du Plateau Sud-brésillien. École des Hautes Études en Sciences Sociales. Paris. (Tese Doutorado).

- 1983-84. Variáveis para a definição e a caracterização das tradições pré-cerâmicas Humaitá e Umbu. Revista do IFCH-UFRGS, n. 11-12, p. 205-15.

. 1991. Origens da ocupação pré-histórica do Rio Grande do Sul na transição PleistocenoHoloceno. In: KERN, Arno (ed.). Arqueologia pré-histórica do Rio Grande do Sul. Porto Alegre. p. 89-102.

KRIEGER, Alex D. 1964. Early Man in the New World. In: JENNINGS, J.D. \& NORBECK, E. (eds.). Prehistoric man in the New World. Chicago: University of Chicago Press. p. 23-81.

LAFORCADA, Gregorio 1974. Yacimiento de Piedra Pelada, Río Arapey. Actas do $3^{\circ}$ Congreso Nacional de Arqueología - Montevideo.

LOTHROP, Samuel K. 1932. Indians of the Paraná delta, Argentina. Anals of the New York Academy of Sciens, v. 33, p. 77-232.

MASEO, Carlos T. 1977. Investigaciones arqueológicas. Montevideo.

MENGHIN, Oswald 1956. El Altiparanaense. Ampurias, n. 17-18, p. 171-200.

. El poblamiento prehistórico de Missiones. Anales de Arqueología y Etnología, Buenos Aires, v. 121, p. 19-40.

MILLER Eurico T. 1987. Resultados preliminares das pesquisas arqueológicas paleoindígena no sul do Brasil ocidental. In: NÚN̄EZ, L. \& MAGGERS, B.J. (eds.). Investigaciones paleoindigenas al sur de la línea ecuatorial. Estudios Atacademños, San Pedro de Atacama, p. 37-61.

- 1967. Pesquisas arqueológicas efetuadas no nordeste de Rio Grande do Sul. In: PRONAPA, Museu Paraense Emilio Goeldi. Publicações Avulsas, v. 1, p. 15-26.

. 1969. Resultados preliminares das escavações no sítio pré-cerâmico RS-LN-1: Cerrito Dalpiaz (abrigo-sob-rocha). Iheringia, Antropologia, n. 1, p. 42-112.

- 1976. Resultados preliminares das pesquisas arqueológicas paleoindígenas no Rio Grande do Sul, Brasil. Actes, $41^{\circ}$ Congresso Internacional dos Americanistas, v. 3, p. 483-91.

NAUE, Guilherme 1973. Dados sobre o estudo dos cerritos na área meridional da Lagoa dos Patos, Rio Grande-RS. Veritas, Porto Alegre, PUCRS, n. 71, p. 1-24.

PENINO, Raúl \& SOLLAZO, Alfredo. 1927. El paradero charrúa del Puerto de las Tunas, y su alfarería. Revista de la Sociedad "Amigos de la Arqueologia, Montevideo, v. 1, p. 151-61.

PRIETO, O.; ALVAREZ, A.; ARBENOIZ, G.; SANTOS, J.; SCHMITZ, P. I.; BASILE BECKER, I. \& NAUE, G. 1970. Informe preliminar sobre investigaciones arqueológicas en el Depto. de Treita y Tres, R.O. Uruguay. Publicações Avulsas, São Leopoldo, IAP/UNISINOS.

RIBEIRO, Pedro M. 1979. Indústrias líticas do sul do Brasil: tentativa de esquematização. Veritas, v. 24, n. 96, p. 471-92.

1990. A tradição Umbu no sul do Brasil. Anais da $5^{\text {a }}$ Reunião Científica da Sociedade Arqueológica Brasileira-Santa Cruz do Sul. Revista do CEPA, v. 7, n. 20, p. 129-56.

RODRIGUEZ, Jorge \& RODRIGUEZ, Amilcar. 1985. Proyecto antropológico-ecológico Salto Grande: Primer informe. Universidad Nacional de Entre Rios. 
RODRIGUEZ, Jorge A. 1992. Arqueología del sudeste de Sudamérica. In: MEGGERS, B.J. (ed.). Prehistória Sudamericana: nuevas perspectivas. p. 177-210.

SCHMITZ, Pedro I. \& BAEZA, Jorge. 1982. Santa Vitoria do Palmar: una tentativa de evolución del ambiente en el arroyo Chuy y su vinculación al problema de los cereritos. Actas do $7^{\circ}$ Congreso Nacional de Arqueología - Montevideo. p. 112-27.

SCHMITZ, Pedro I.; NAUE, Guilherme \& BASILE BECKER, Itala I. 1991. Os aterros dos campos do sul: a tradição Vieira. In: KERN, Arno (ed.). Arqueologia pré-histórica do Rio Grande do Sul. Porto Alegre.

SCHMITZ, Pedro I. 1976. Sítios de pesca laustre em Rio Grande-RS, Brasil. São Leopoldo: Instituto Anchietano de Pesquisas.

. 1978. Indústrias líticas en el sur de Brasil. Estudos Leopoldenses, v. 14, n. 47, p. 103-29.

. 1984. Caçadores-coletores do Sul. In: Caçadores-coletores da pré-história do Brasil. São Leopoldo: IAP/UNISINOS.

SCHOBINGER, Joan. 1969. Prehistoria de Suramerica. Barcelona: Labor.

SERRANO, Antonio. 1932. Exploraciones arqueológicas en el Río Uruguay medio. Memorias del Museo de Paraná. Arqueología 2.

.1933. Las culturas protohistóricas del este argentino y Uruguay. Memorias del Museo de Paraná v. 7, p. 1-44.

.1950. Los primitivos habitantes de "Entre Ríos". Biblioteca Entrerriana, Serie História II, Paraná.

.1972. Líneas fundamentales de la arqueología del Litoral. Una tentativa de periodización. Universidad Nacional de Córdoba, Instituto de Antropología 32.

SOSA, Maruca R. 1957. La Nación Charrúa. Montevideo.

TADDEI, Antonio; CAMPOS, Juan \& BOSCH, Ademar. 1977. Las industrias líticas arqueológicas de los ríos Tacuarembó Grande y Chico. Actas do $5^{\circ}$ Encuentro de Arqueología del Litoral - Fray-Bentos. p. 225-244.

TADDEI, Antonio. 1969. Un yacimiento de cazadores superiores del medio Río Negro, Uruguay. Anais do $3^{\circ}$ Simpósio de Pesquisas-São Leopoldo. Estudos Leopoldenses, v. 13, p. $57-78$.

.1980. Un yacimineto de cazadores superiores en el Río Negro (Paso del Puerto). Actas do 3\% Congreso Nacional de Arqueología - Montevideo.

. 1987. Algunos aspectos de la arqueología préhistórica del Uruguay. In: NUÑEZ, L. \& MEGGERS, B.J. (eds.). Investigaciones al sur de la línea ecuatorial. Estudios Atacameños, San Pedro de Atacama, v. 8, p. 69.

TORRES, Luis M. 1911. Los primitivos habitantes del delta del Paraná. Biblioteca Centenaria de la Universidad Nacional de la Plata, Buenos Aires, v. 4.

TUYA DE MAESO, Leila C. 1980. Cerámica indígena de la $R$ O. del Uruguay. Consideraciones sobre la cerámica de yacimientos arqueológicos investigados en los Departamentos de Colonia, Soriano y Río Negro. Decoración, expresiones zoomarfas, Montevideo.

WILLEY, Gordon. 1971. An introduction to American Archeology. South America, New Jersey, v. 2.

. 1978. Estimated correlation and dating of South and Central American culture sequences. American Antiquity, v. 32, n. 4, p. 353-78. 